\title{
Radial Head Arthroplasty: Does Ligaments Repair Influence Outcomes? A Minimum Two Years Follow- Up Radiographic Multi-Center Study
}

Cristina Galavotti ( $\sim$ galavotticristina@gmail.com )

Ortopedia POC - ASST Cremona https://orcid.org/0000-0001-9828-9882

\section{Sara Padovani}

Ortopedia - Ospedale degli Infermi Faenza

\section{Alessandro Nosenzo}

Ortopedia - Ospedale Civile di Guastalla

Margherita Menozzi

Ortopedia - Ospedale Civile di Guastalla

\section{Pietro Maniscalco}

Ortopedia AUSL Ospedale di Piacenza

\section{Galeazzo Concari}

Ortopedia - Ospedale di Vaio Fidenza

\section{Clemente Villani}

Ortopedia - Ospedale S. Maria Nuova Reggio Emilia

\section{Ettore Sabetta}

Ortopedia - Ospedale S. Maria Nuova Reggio Emilia

\section{Alberto Belluati}

Ortopedia - Ospedale S. Maria delle Croci Ravenna

\section{Mauro Monesi}

Ortopedia - Ospedale M. Bufalini Cesena

\section{Leo Massari}

Ortopedia - A.O.U. Ferrara

\section{Carlotta Pari}

Ortopedia - Ospedale S. Maria delle Croci Ravenna

\section{Michele Cavaciocchi}

Ortopedia - Ospedale degli Infermi Faenza

\section{Filippo Calderazzi}

Clinica Ortopedica - A.O.U. Parma

\section{Alessandra Colozza}

Ortopedia - Ospedale degli Infermi Faenza 


\section{Research Article}

Keywords: Radial head prostheses, ligament repair, elbow stability, revision rate

Posted Date: April 14th, 2021

DOl: https://doi.org/10.21203/rs.3.rs-418402/v1

License: (c) (i) This work is licensed under a Creative Commons Attribution 4.0 International License. Read Full License

Version of Record: A version of this preprint was published at European Journal of Orthopaedic Surgery \& Traumatology on April 24th, 2021. See the published version at https://doi.org/10.1007/s00590-02102979-1. 


\section{Abstract}

\section{Purpose:}

The current indication for comminuted radial head fractures is radial head arthroplasty (RHA). The main purpose of this study was to investigate any statistical differences in terms of prosthesis revision or removal and radiographic-degenerative changes by comparing patients who underwent RHA and ligaments repair to those who underwent only RHA implant at minimum two-years follow up. The secondary aim was to delineate a trend profile of RHA implants.

\section{Methods:}

All patients who underwent RHA surgery for traumatic pathology between January 2012 and December 2017 were eligible. Two researchers independently and retrospectively reviewed the patients' charts and collected the following data: type of prosthesis, associated surgical procedures and revision surgery. They also looked for any radiographic sign of prosthesis loosening, overstuffing, capitellar osteopenia, heterotopic ossification and degenerative changes. No clinical evaluation was performed.

\section{Results:}

In six years 124 RHA were implanted (74 Female, 50 Male, mean age 56). The main diagnoses were: terrible-triad, trans-olecranon fracture and isolated radial head fracture. It was found no significant statistical difference between the two groups, nevertheless the cohort of patients that underwent ligaments repair had a lower revision rate in comparison to the other. Suture of the annular ligament seems to be critical. The overall revision rate was $10.5 \%$.

\section{Conclusion:}

This multi-center study found no evidence that ligaments repair, as an associated surgical procedure, improves RHA longevity, except for annular ligament. Nevertheless, it seems to prevent degenerative changes at mid-term follow-up.

\section{Introduction}

Radial head arthroplasty (RHA) is recommended for un-repairable radial head fractures alone or in association with other elbow lesions or forearm instability [1]. Radial head, as a secondary stabilizer, maintains the physiological elbow kinematics and biomechanics, resisting valgus and posterolateral forces and preventing proximal migration of the radius [2]. Radial head resection might be still considered a valid option, indeed there are several studies reporting good results at long-term follow-up. Nevertheless, RHA is currently considered the most suitable surgical indication for Mason type III and IV radial head fractures and for complex elbow instabilities [3]. In fact, as Marinelli et al described in their study, RHA plays a crucial role both in short and medium/long period: during the first two-three weeks the RHA maintains the elbow reduced and stable, which allow correct soft tissue stabilizers healing and early 
mobilization; over subsequent months and years RHA prevents ulno-humeral arthritis, valgus deformity and tardy ulnar nerve symptoms [4].

Many studies report the importance of elbow ligaments repair, but very few compare it with RHA and analyse its influence on removal/revision rate [5-9]. Correct positioning and size of the implant remains a current challenge for the surgeon. In daily orthopaedic practice, standardized anteroposterior and lateral radiographs are carried out postoperatively and during follow-up to evaluate implant positioning. Numerous studies have reported radiographic abnormalities after RHA; some of these reported a correlation between radiographic changes and functional outcomes, but others demonstrated how radiographic deficiencies do not affect the clinical results [10-12].

The main aim of the study was to compare a group of patients who underwent RHA and ligaments repair and the cohort that underwent only prosthesis implant, in order to detect any statistical differences in terms of prosthesis removal or revision. A secondary objective was to delineate a trend profile of RHA implants and radiographic changes at minimum two years follow-up (FU).

This retrospective multi-center study was approved by local ethics committee.

\section{Materials And Methods}

The medical records of patients treated between January 2012 and December 2017 in eight orthopaedic departments in northern Italy were retrospectively analysed. Inclusion criteria were patients who underwent implantation of RHA for type III or IV radial head fracture according to Mason classification and a minimum follow up of two-years [13]. There were no age limitations. Exclusion criteria were RHA performed for chronic diseases and patients affected by Essex-Lopresti lesion, because it has a different etiopathogenesis.

Due to the absence of RHA register, data collection was organized as follows: all surgery reports were downloaded for each department, using the computerized system. As there is no univocal identification code for "radial head prosthesis", the research was initially wider, including diagnoses and treatments that could include the words "radial head", and subsequently filtered. Two researchers independently and retrospectively, reviewed the patients' charts and collected the following data: sex, age, initial diagnosis, type and features of the implant used, associated surgical procedures, such as ligaments repair, coronoid process and ulna fixation. Ligament repair (annular ligament, lateral collateral ligament LCL and medial collateral ligament $\mathrm{MCL}$ ) was intended as any acute surgical procedure (suture, re-tensioning, re-insertion) without specifying the technique used. Complications as removal or revision surgery and time elapsed from primary surgery were reported. For all cases that matched the inclusion criteria, pre- and postsurgery radiographs, one month post-operative $x$-ray and final follow up images were downloaded from the radiology files archive in every centre, in order to detect: heterotopic ossifications, any sign of prosthesis loosening around the stem, capitellar osteopenia, over-lengthening and joint over-stuffing and degree of arthritic changes. For those patients who had undergone further operations, also the subsequent surgical procedure reports and radiographs were also collected and analysed. Heterotopic 
ossifications were graded according to llahi-Gabel classification [14]. Prosthesis loosening was described as none, mild, moderate or severe based on the number of zones involved (from one to seven) and thickness (in millimeters) of observed areas [15]. RHA overstuffing and over lengthening were positive if prostheses head profile exceeds a line tangent to the lateral humeral condyle and a line tangent to the radio-humeral joint [16]. Capitellar osteopenia was recorded as none, mild, moderate or severe. Arthritic changes were classified as described by Broberg and Morrey's classification [17]. No clinical evaluation was performed.

\section{Statistical Analysis}

Data analysis was performed using the commercial package IBM-SPSS v.26@ and the open source statistical system Jamovi v.1.6.7. Statistical summaries were calculated for all the variables in the data set. If relevant, standard errors and the corresponding $95 \%$ confidence intervals were also estimated. Comparisons between the groups of continuous variables were performed using both parametric tests (Student's t-test, repeated measures ANOVA) and non-parametric test (Mann-Whitney's U-test).

Comparison s between categorical variables were performed using the chi-square test and Fisher's exact test. For both continuous and categorical variables, the results were considered statistically significant for a $p$-value less than $5 \%(p<0.05)$. To take into account potential confounders, univariate analysis has been followed by a multivariate analysis. A logistic regression was performed using the revision of the prosthesis as dependent variable, and center, prosthesis type, ligament repair (annular ligament, LCL and MCL repair) as factors and covariates.

\section{Results}

From January 2012 to December 2017, 124 RHA were implanted in the eight hospitals recruited; in each orthopaedic unit all operations were performed by a surgeon experienced in elbow pathology. Demographic data, diagnosis and prosthetic models are shown in table 1.

Overall $13(10,5 \%)$ patients had RHA removed or replaced after 25,5 months on average (min $2, \max 72$, median 24); the main reasons of implant failure were aseptic loosening in six patients $(4,8 \%)$, overlengthening of the implant with joint over-stuffing in five (4\%) and head-stem dissociation in other two $(1,6 \%)$ [Fig 1]. Excepted for one revised case (in which the head size of the prosthesis was decreased), all the other prostheses were removed as the elbow was judged to be stable during surgery. No correlation was found between the removal/revision rate and the prosthetic model. Eight other patients underwent secondary surgery, five of them because of elbow stiffness whereas other three had persistent instability.

The final radiographic follow up was performed 31,8 months after surgery on average (min 24 , max 100 , median 24) and radiographic features analysed are shown in table 2 . A statistically significant correlation $(p<0,001)$ was observed between overstuffing and capitellar osteopenia. No correlation was found between the initial diagnosis patterns and the presence of over-stuffing, capitellar osteopenia or arthritis in the final $\mathrm{x}$-ray; on the contrary, there was a statistically significant correlation between the complexity of first diagnosis and heterotopic ossification $(p<0,02)$. 
Among the 13 removed or revisioned cases, seven had overstuffing, eight had moderate and severe loosening around the stem, five had moderate and severe capitellar osteopenia and nine had grade 2 and 3 degenerative arthritis of the joint; in conclusion loosening areas and arthritis changes were the only two parameters that significantly influenced the removal/revision rate (with $p<0,001$ and $p: 0,002$ respectively).

Analysing the surgery registers we found out that annular ligament was repaired in $66,1 \%$ of cases, lateral collateral ligament (LCL) in 59,7\% and medial collateral ligament (MCL) in $21 \%$. In Mason type III fractures LCL was repaired in $63(62,4 \%)$ patients, MCL in $22(21,8 \%)$ patients and annular ligament in 67 $(66,3 \%)$; whereas in Mason type IV fracture-dislocation LCL was fixed in $11(47,8 \%)$ cases, MCL in four $(17,4 \%)$ and annular ligament in $15(65,2 \%)$. In all cases comparison between Mason's classification and ligament repair did not show a significant $p$ value. The overall removal/revision rate was $10,5 \%$ (13 patients), among these patients LCL was not repaired in seven (14\%), MCL was not fixed in $11(11,2 \%)$ and the annular ligament was not sutured in eight $(19,1 \%)$. The suture of annular ligament was crucial in order to decrease the removal/revision rate ( $p$ value: 0,02$)$ (table 3 ).

To take into account the effect of potential confounders, such as the different centers where the surgery was performed or the type of prosthesis used, univariate analysis has been followed by a multivariate analysis. A binary logistic regression was performed using the revision of the prosthesis (yes, no) as dependent variable, and center, prosthesis type, ligament repair (annular ligament, LCL and MCL repair) as predictors. The results obtained by the logistic regression have confirmed the previous finding of the univariate analysis. The only statistically significant predictor seems to be the repair of the annular ligament $(p=0.024, O R=11.2)$.

\section{Discussion}

This retrospective multi-centre study reports the radiographic characteristics of RHA and a revision rate surgery of 10,5\% at two-year follow-up. The comparison between groups shown that patients who underwent annular ligament repair, as associated surgical procedure, have a significant statistical difference, in term of RHA survival.

The RHA is indicated in un-reconstructible Mason type III and IV and in those elbow injuries where the radial head, as a secondary stabilizer, becomes essential. No guidelines have been published yet to suggest which prosthetic model is the most suitable depending on the diagnosis or which design is the most suitable.

Different kinds of stem can be implanted, such as loose-fit, press-fit and cemented stems; monopolar and bipolar designs are also available as well as spherical or anatomical heads. There are no studies demonstrating the superiority of a model on the others, but many report how the correct size (such as diameter and height of the head) is determinant for final outcome $[18,19]$. Some authors prefer bipolar prosthesis because it better restore the tracking with the capitellum; other authors are convinced of monopolar design superiority because of the construct stability $[16,20]$. However, bipolar implants have 
some peculiar risks, such as components dissociation and polyethylene osteolysis. Our study compared only press-fit and loose-fit stems and we did not find one to be superior to the other, although we did not analyse functional outcomes but only radiographic results.

A mean $10 \%$ removal/revision rate is reported in literature and it occurs within two years from primary surgery on average; the main causes are aseptic loosening of the implant and pain [5]. Pain is a symptom, not the cause and it might be explained by many reasons. O'Driscoll and Herald suggested that proximal forearm pain in patients with press-fit RHA is a strong symptomatic loosening indicator, even in absence of radiographic loosening signs [21]. Moreover, this study revealed that intentionally loose-fit positioned prostheses failed earlier, if compared to press-fit implants (failure occurs after an average of 17 and 53 months, respectively).

Other causes of removal/revision implant are stiffness with heterotopic ossifications, impingement associated with overstuffing and persistent clinical instability [12,20,22].

It has been shown that the minimum follow-up required to fully evaluate the complications after RHA is 39 months [23]. Viveen et al., in a recent systematic review, revealed that the most frequent causes of RHA failure are symptomatic aseptic loosening (30\%), stiffness (20\%) and persistent pain (17\%), they also reported that failure occurred after 34 months on average [20].

The results of our study are in line with those of the literature; we report a revision/removal rate of $10,5 \%$ and an average time to failure of 24 months; our main failure causes are aseptic loosening and implant overstuffing.

VanRiet et al. showed that the timing of RHA positioning is the main factor influencing the appearance of osteolysis of the capitellum; prostheses implanted 6 months after the initial trauma are associated with clear radiographic signs of erosion [22]. In our study, most patients do not have or have slight signs of bone resorption of the capitellum: this happened probably because all the prostheses have been placed in acute; however, it has been confirmed in our study, that those who show a serious compromised capitellum have overstuffing.

Aseptic loosening is a frequent problem: radiolucencies around the stem are typical in zones one and seven and seem to occur mostly early after implantation, generally between the first and fifteenth postoperative months. Subcollar resorption could affect both press-fit and loose-fit stem, but it is often reported with press-fit prostheses and seems to be stationary after one or two years, without progression and without clinical symptoms [24].

An innovative datum that emerged from our study, is the importance of ligament reconstruction time related to RHA, in particular the execution or not of some type of surgical procedures on the lateral, medial collateral ligament and on the annular ligament. In literature, although there are several studies that underscore the importance of ligament repair, only few focus on the relation with RHA [5,6,22]. Hackl et al in their multi-center retrospective analysis of 466 cases, showed that one of the most common 
causes of revision was instability; they found 170 unstable elbows, 65 of them had stage II to III posterolateral rotatory instability, 38 valgus instability, 28 multidirectional instability, 19 varus posteromedial rotatory instability, nine longitudinal forearm instability, nine persisting elbow dislocation and two proximal radioulnar instability [7]. They also highlighted that instability is directly related to the severity of the initial trauma, especially in case of Mason type IV fractures, terrible-triad injuries and Monteggia-like injuries. Delclaux et al described that instability is related to LCL complex failure most of the times; only lateral ligaments suture with a radial head prosthesis can restore elbow stability close to normal [8]. Elbow stability can be influenced also by the type of prosthesis: monopolar prostheses have shown to better restore stability than bipolar prostheses $[9,25]$.

In our study, we assessed the type of radial head fracture according to Mason's classification: in Mason type IV, due to elbow dislocation, LCL should always be repaired or at least tested; in Mason type III, LCL repair might not be performed in condition of a proven joint stability. The MCL repair depends on initial traumatic mechanism, whereas the annular ligament should always be sutured as it is damaged by the fracture or by the surgical access. From our data it clearly emerges that if ligament time is not performed, the removal/revision rate is higher; however, only the correlation with annular ligament suture was statistically significant; in fact, annular ligament is essential to ensure normal prosthesis-capitellum tracking. Wapler et al found that when RHA is used, MCL tears, that occurs with severe radial head trauma, can heal even if it is not directly repaired; according to them it seems justified to restore the elbow's stability with a RHA without repairing the MCL surgically [26].

Our study has several weaknesses: firstly, it is retrospective and no clinical evaluation was performed: this prevented us from analyzing the correlation between the revision/removal rate and the presence of pain. Secondly, despite it is a multi-centric study, it includes very heterogenous cases with a wide range of diagnosis, several prostheses models and different surgeons. Furthermore, the ligament repair data could be underestimated since surgeons might have them omitted from surgery's reports (too predictable to be mentioned).

Further studies are required to demonstrate the importance of ligamentous component during radial head replacement. Since registers for other joints prosthesis already exist, in order to encourage next studies, we recommend the creation of a regional/national RHA register.

\section{Conclusions}

In conclusion, this multi-center study found no evidence that ligaments repair, as an associated surgical procedure, improve RHA longevity, except for annular ligament suture; but it seems to prevent radiographic degenerative changes at mid-term follow-up.

\section{References}


1. Laumonerie P, Reina N, Gutierrez C, Delclaux S, Tibbo ME, Bonnevialle N et al. (2018) Tight-fitting radial head prosthesis: does stem size help prevent painful loosening? International Orthopaedics 42,161-167.

2. AR Kachooei, FM.A.P. Claessen, SM. Chase, K K.J. Verheij, C.N van Dijk, D Ring. (2016) Factors associated with removal of a radial head prosthesis placed for acute trauma. Injury 47(6):1253-1257.

3. Antuña SA, Sánchez-Márquez JM, Barco R. (2010) Long-term results of radial head resection following isolated radial head fractures in patients younger than forty years old. J Bone Joint Surg Am 92(3):558-66.

4. Marinelli A, Guerra E, Ritali A, Cavallo M, Rotini R. (2017) Radial head prosthesis: surgical tips and tricks. Musculoskelet Surg 101(Suppl 2):187-196.

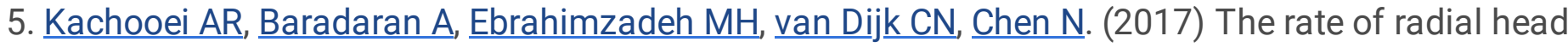
prosthesis removal or revision: a systematic review and meta- analysis. J hand Surg Am 43(1):3953.e1.

6. Strelzow JA, Athwal GS, MacDermid JC, Grewal R, Faber KJ, Drosdowech D et al. (2017) Effect of concomitant elbow injuries on the outcomes of radial head arthroplasty: a cohort comparison. Journal Orthop Trauma 31(10):e327-e333.

7. Hackl M, Wegmann K, Hollinger B, El-Zayat B F, Seybold D, Guhring T, et al. (2018) Surgical revision of radial head fractures: a multicenter retrospective analysis of 466 cases. J Shoulder Elbow Surg 28(8):1457-1467.

8. Delclaux S, Lebon J, Faraud A, Toulemonde J, Bonnevialle N, Coulet B et al. (2015) Complications of radial head prostheses. Int Orthop 39(5):907-13.

9. Chanlalit C, Shukla DR, Fitzsimmons JS, Thoreson AR, An KN, O'Driscoll SW. (2011) Radiocapitellar stability: the effect of soft tissue integrity on bipolar versus monopolar radial head prostheses. $J$ Shoulder Elbow Surg 20:219-225.

10. Ha AS, Petscavage JM, Chew FS. (2012) Radial head arthroplasty: a radiologic outcome study. AJR Am J Roentgenol. 199(5):1078-82.

11. Levy JC, Formaini NT, Kurowicki J. (2016) Outcomes and radiographic findings of anatomic press-fit radial head arthroplasty. J Shoulder Elbow Surg. 25(5):802-9.

12. Claessen FMAP, Bexkens R, Kodde IF, Doornberg JN, Bekerom MPJVD, Eygendaal D. (2020) Radiographic predictors for short-term functional outcome after radial head arthroplasty in patients with persistent symptoms after treatment for radial head. Arch Bone Jt Surg. 8(1):27-32.

13. Mason ML. (1954) Some observations on fracture of the head of the radius with a review of one hundred cases. Br J Surg 42(172):123-132.

14. Ilahi OA, Bennett JB, Gabel GT, Mehlhoff TL, Kohl HW 3rd. (2001) Classification of heterotopic ossification about the elbow. Orthopedics 24(11):1075-1077.

15. Grewal R, MacDermid JC, Faber KJ, Drosdowech DS, King_GJ. (2006) Comminuted radial head fractures treated with a modular metallic radial head arthroplasty. J. Bone Joint Surg Am 88(10):2192-2200. 
16. Rotini R, Marinelli A, Guerra E, Bettelli G, Cavaciocchi M. (2012) Radial head replacement with unipolar and bipolar SBi system: a clinical and radiographic analysis after a 2-year mean follow-up. Musculoskelet Surg 96 (suppl 1):S69-S79.

17. Broberg MA, Morrey BF. (1986) Results of delayed excision of the radial head after fracture. J Bone Joint Surg Am 68(5):669- 674.

18. Moro JK, Werier J, MacDermid JC, Patterson SD, King GJ. (2001) Arthroplasty with a metal radial head for unreconstructible fractures of the radial head. J Bone Joint Surg 83(8):1201-11

19. Popovic N, Gillet P, Rodriguez A, Lemaire R. (2000) Fracture of the radial head with associated elbow dislocation: results of treatment using a floating radial head prosthesis. J Orthop Trauma 14(3):1717.

20. Viveen J, Kodde IF Heijink A, Koenraadt KLM, van den Bekerom MPJ, Eygendaal D. (2019) Why does radial head arthroplasty fail today? A systematic review of recent literature. EFORT Open Rev 4(12):659-667.

21. O'Driscoll SW, Herald JA. (2012) Forearm pain associated with loose radial head prostheses. J Shoulder Elbow Surg 21(1):92-7.

22. van Riet RP, Sanchez-Sotelo J, Morrey BF. (2010) Failure of metal radial head replacement. J Bone Joint Surg Br 92(5):661-7.

23. Laumonerie $P$, Reina $N$ Kerezoudis $P$ Declaux $S$, Tibbo ME Bonnevialle $N$ et al. (2017) The minimum follow-up required for radial head arthroplasty. A meta-analysis. Bone Joint J 99-B(12):1561-1570.

24. Kodde IF, Heijink A, Kaas L, Mulder PG, van Dijk CN, Eygendaal D. (2016) Press-fit bipolar radial head arthroplasty: midterm results. J Shoulder Elbow Surg 25(8):1235-42.

25. A. Nosenzo, C. Galavotti, M. Menozzi, A. Garzia, F. Pogliacomi, F. Calderazzi (2020) Acute radial head replacement with bipolar prostheses: midterm results. Eur J Orthop Surg Traumatol doi: 10.1007/s00590-020-02774-4

26. Wapler C, Fontaine C, Mesnil P, Chantelot C. (2016) Medial collateral ligament healing after posttraumatic radial head arthroplasty: A retrospective study of 33 cases with a mean follow-up of 73 months. Hand Surg Rehabil 35(1):44-50.

\section{Tables}




\begin{tabular}{|c|c|}
\hline STUDY PATIENTS (n: 124) & \\
\hline Sex & $\begin{array}{l}\text { Female: } 74(59,7 \%) \\
\text { Male: } 50(40,3 \%)\end{array}$ \\
\hline Age (years) & Mean $56(\min 21, \max 86$, median 58$)$ \\
\hline Diagnosis & $\begin{array}{l}\text { Isolated radial head fracture: } 27(21,7 \%) \\
\text { Terrible-triad: } 71(57,3 \%) \\
\text { Trans-olecranon fracture-dislocation: } 26(21 \%)\end{array}$ \\
\hline RHA stem & $\begin{array}{l}\text { Press-fit: } 83(67 \%) \\
\text { Loose-fit: } 30(24,2 \%) \\
\text { Cemented: } 11(8,8 \%)\end{array}$ \\
\hline RHA type & $\begin{array}{l}\text { rHead RECON SBI Stryker: } 61(49,2 \%) \\
\text { ExploR Radial Head Zimmer: } 4(3,2 \%) \\
\text { RHSTM TORNIER: } 18(14,5 \%) \\
\text { EVOLVE } \\
\text { Anatomic Radial Head System Acumed: } 11(8,9 \%)\end{array}$ \\
\hline $\begin{array}{l}\text { Interval first surgery - removal } \\
\text { / revision (months) }\end{array}$ & Mean $25,5(\min 2, \max 72$, median 24$)$ \\
\hline $\begin{array}{l}\text { Radiographic follow-up } \\
\text { (months) }\end{array}$ & Mean $31,8(\min 24, \max 100$, median 24$)$ \\
\hline
\end{tabular}

Table 1 Demographic data, diagnosis and prosthetic models 


\begin{tabular}{|l|l|}
\hline RADIOGRAPHIC TABLE & \\
\hline Heterotopic Hossification $^{1}$ & $\begin{array}{l}\text { Grade 0: } 87(70,2 \%) \\
\text { Grade I: } 10(8,1 \%) \\
\text { Grade II: } 6(4,8 \%) \\
\text { Grade III: } 20(16,1 \%) \\
\text { Grade IV: } 1(0,8 \%)\end{array}$ \\
\hline Prosthesis loosening $^{2}$ & None: $64(51,5 \%)$ \\
& Mild: $45(36,3 \%)$ \\
& Moderate: $8(6,5 \%)$ \\
& Severe: $7(5,7 \%)$ \\
\hline Capitellar osteopenia $^{3}$ & None: $62(50 \%)$ \\
& Mild: $41(33,1 \%)$ \\
& Moderate: $15(12,1 \%)$ \\
& Severe: $6(4,8 \%)$ \\
\hline Over-lengthening / Over-stuffing $^{4}$ & Yes: $48(38,7 \%)$ \\
& No: $76(61,3 \%)$ \\
\hline Arthritic changes $^{5}$ & Grade $0: 35(28,2 \%)$ \\
& Grade I: $56(45,2 \%)$ \\
& Grade II: $26(21 \%)$ \\
& Grade III: $7(5,6)$ \\
\hline
\end{tabular}

1 Heterotopic Hossification, Ilahi and Gabel's classification [14] (angle subtended by the largest area of ectopic fragment on lateral radiograph measuring from the centre of rotation):

- Grade 0: none

- Grade I: $<30^{\circ}$

- Grade II: $30^{\circ}-60^{\circ}$

- Grade III: $>60^{\circ}$

- Grade IV: ulno-humeral ankylosis on any $\mathrm{x}$-ray view

2 Prosthesis loosening [15] based on the number of areas involved (from one to seven) and thickness (in millimeters) of observed areas:

- None: absent

- Mild: 1 or 2 areas; thickness $<2 \mathrm{~mm}$

- Moderate: $3-6$ areas; thickness $\geq 2 \mathrm{~mm}$

- Severe: involvement of all 7 areas

3 Capitellar osteopenia was recorded as none, mild, moderate or severe from $\mathrm{x}$-ray view

4 Over-lengthening - Over-stuffing [16] were negative (NO) or positive (YES) if prostheses head profile exceeds a line tangent to the lateral humeral condyle and a line tangent to the radio-humeral joint

5 Arthritic changes, Broberg and Morrey's classification [17]

- Grade 0: normal joint

- Grade I: slight narrowing of the joint space with minimal osteophytes

- Grade II: moderate narrowing of the joint space with osteophytes

- Grade III: severe degenerative changes with joint destruction

Table 2 Radiographic features at final $\mathrm{x}$-ray follow-up 


\begin{tabular}{|c|c|c|c|c|c|c|c|c|}
\hline & & & \multicolumn{2}{|c|}{ Annular Ligament } & \multicolumn{2}{|c|}{ LCL } & \multicolumn{2}{|c|}{ MCL } \\
\hline & & & No & YES & No & YES & No & YES \\
\hline \multirow{4}{*}{ a) } & \multicolumn{2}{|c|}{$\begin{array}{c}\text { Mason III } \\
\text { n } 101 \\
(81,5 \%)\end{array}$} & $\begin{array}{c}34 \\
(33,7 \%)\end{array}$ & $\begin{array}{c}67 \\
(66,3 \%)\end{array}$ & $\begin{array}{c}38 \\
(37,6 \%)\end{array}$ & $\begin{array}{c}63 \\
(62,4 \%)\end{array}$ & $\begin{array}{c}79 \\
(78,2 \%)\end{array}$ & $\begin{array}{c}22 \\
(21,8 \%)\end{array}$ \\
\hline & \multicolumn{2}{|c|}{$\begin{array}{c}\text { Mason IV } \\
\text { n 23 } \\
(18.5 \%)\end{array}$} & $\begin{array}{c}8 \\
(34,8 \%)\end{array}$ & $\begin{array}{c}15 \\
(65,2 \%)\end{array}$ & $\begin{array}{c}12 \\
(52,2 \%)\end{array}$ & $\begin{array}{c}11 \\
(47,8 \%)\end{array}$ & $\begin{array}{c}19 \\
(82,6 \%)\end{array}$ & $\begin{array}{c}4 \\
(17,4 \%)\end{array}$ \\
\hline & \multicolumn{2}{|c|}{ TOT } & $\begin{array}{c}42 \\
(33,9 \%)\end{array}$ & $\begin{array}{c}82 \\
(66,1 \%)\end{array}$ & $\begin{array}{c}50 \\
(40,3 \%)\end{array}$ & $\begin{array}{c}74 \\
(59,7 \%)\end{array}$ & $\begin{array}{c}98 \\
(79 \%)\end{array}$ & $\begin{array}{c}26 \\
(21 \%)\end{array}$ \\
\hline & \multicolumn{2}{|c|}{$p$ values } & \multicolumn{2}{|c|}{0,91} & \multicolumn{2}{|c|}{0,19} & \multicolumn{2}{|c|}{0,64} \\
\hline \multirow{2}{*}{ b) } & \multirow{2}{*}{$\begin{array}{c}\text { Removal / } \\
\text { Revision }\end{array}$} & $\begin{array}{c}\text { No } \\
\text { n } 111 \\
(89,5 \%)\end{array}$ & $\begin{array}{c}34 \\
(80,9 \%)\end{array}$ & $\begin{array}{c}77 \\
(93,9 \%)\end{array}$ & $\begin{array}{c}43 \\
(86 \%)\end{array}$ & $\begin{array}{c}68 \\
(91,9 \%)\end{array}$ & $\begin{array}{c}87 \\
(88,8 \%)\end{array}$ & $\begin{array}{c}24 \\
(92,3 \%)\end{array}$ \\
\hline & & $\begin{array}{c}\text { YES } \\
\text { n 13 } \\
(10,5 \%)\end{array}$ & $\begin{array}{c}8 \\
(19,1 \%)\end{array}$ & $\begin{array}{c}5 \\
(6,1 \%)\end{array}$ & $\begin{array}{c}7 \\
(14 \%)\end{array}$ & $\begin{array}{c}6 \\
(8,1 \%)\end{array}$ & $\begin{array}{c}11 \\
(11,2 \%)\end{array}$ & $\begin{array}{c}2 \\
(7,7 \%)\end{array}$ \\
\hline & \multicolumn{2}{|c|}{$p$ values } & \multicolumn{2}{|c|}{$0,02^{*}$} & \multicolumn{2}{|c|}{0,29} & \multicolumn{2}{|c|}{0,6} \\
\hline
\end{tabular}

LCL (lateral collateral ligament); MCL (medial collateral ligament); * statistically significant $p<0.05$

Table 3 Comparison between ligament repair and a) Mason's classification b) removal/revision rate

Figures 

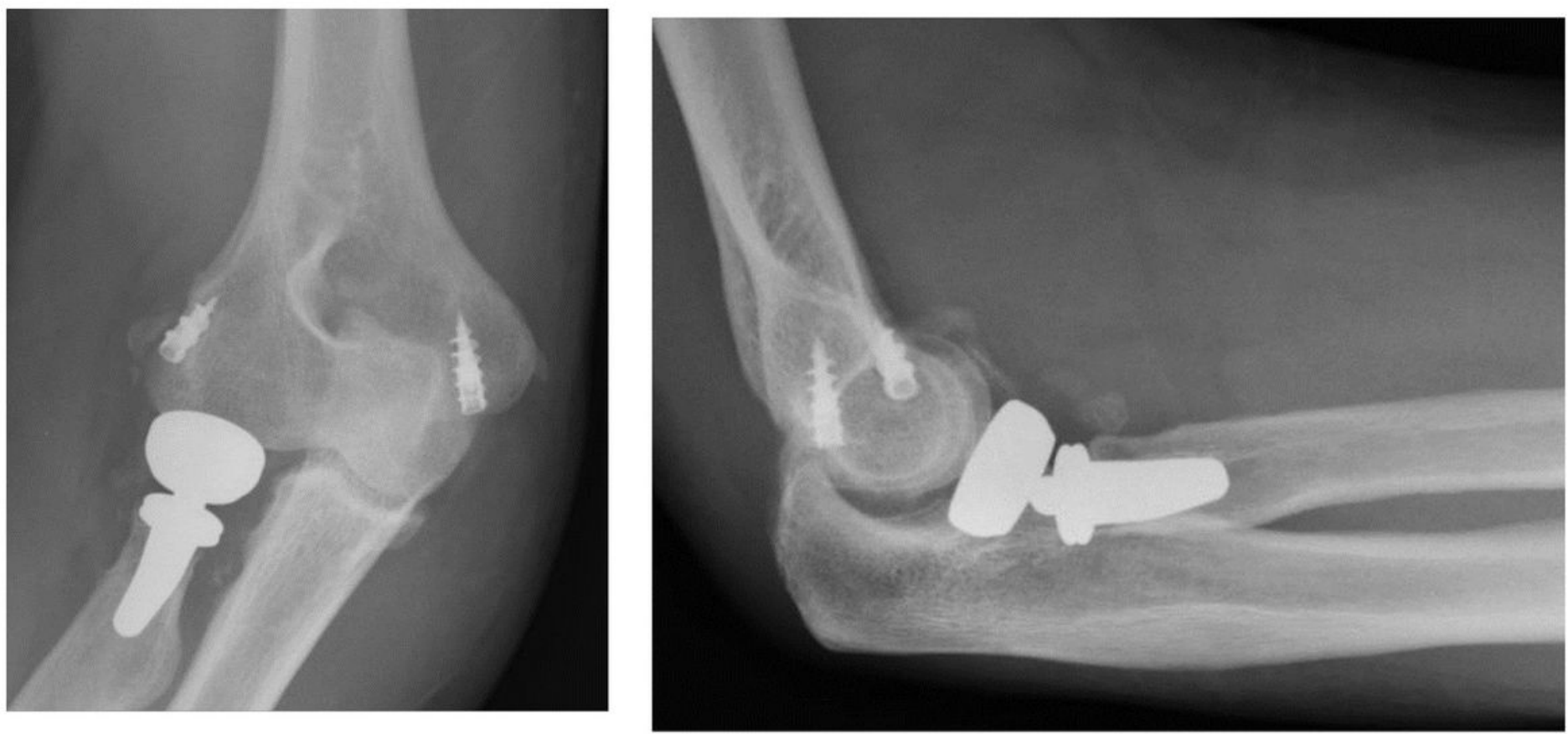

\section{Figure 1}

Left panel: a case of head-stem dissociation on anteroposterior view; Right panel: b case of head-stem dissociation on lateral view 